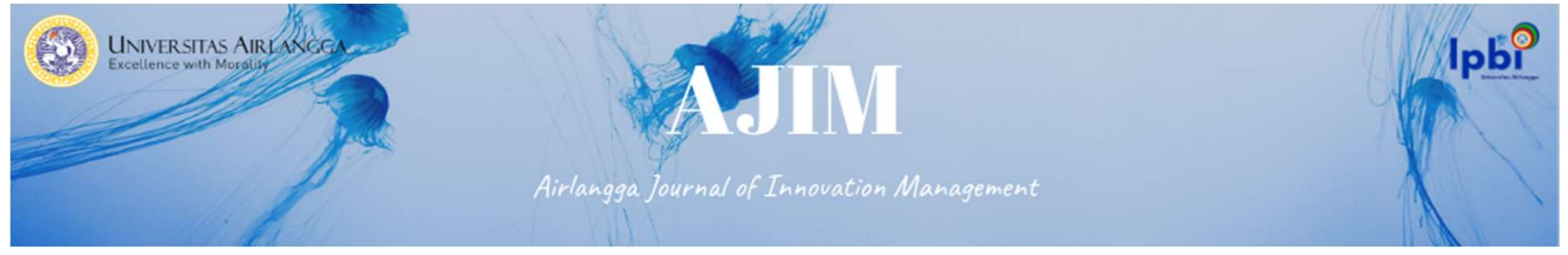

Vol.1 No.2, October 2020

e-ISSN: 2722-5062

DOI: 10.20473/ajim.vi1i.19310

\title{
MEMINIMALKAN BIAYA TRANSPORTASI PENGIRIMAN BARANG PLTS SEISMIC AREA JAWA BARAT DENGAN MENENTUKAN RUTE DISTRIBUSI YANG EFISIEN DENGAN METODE SAVING MATRIX DI PT.XYZ
}

\author{
Hari Fadlisyah ${ }^{1}$, Cahya Laksana Putra ${ }^{2}$, Namun Mulyadi ${ }^{3}$ \\ ${ }^{123}$ Program Studi Teknik Industri Fakultas Teknik Universitas Widyatama \\ JL.Cikutra No.204 A Bandung \\ E-mail korespondensi: Hari kirk10@gmail.com
}

\begin{abstract}
ABSTRAK
Distribusi merupakan salah satu faktor penting bagi perusahaan untuk dapat melakukan pengiriman barang secara tepat ke lokasi proyek, agar kegiatan distribusi barang lebih efisien, maka dilakukan penentuan jalur transportasi dengan metode saving Matrix. Saving Matrix merupakan metode yang digunakan untuk menentukan jarak, rute, waktu atau ongkos dalam pelaksanaan pengiriman barang dengan cara menentukan jalur yang harus dilalui permasalahan dari perusahaan yaitu dalam Pengiriman barang ke lokasi proyek. Penelitian ini adalah jenis penelitian kuantitatif dengan metode kalkulasi Saving Matrix. Hasil penelitian menyatakan bahwa proses pendistribusian barang dalam satu kali pengiriman barang ke lokasi proyek dilakukan tanpa melihat terlebih dahulu dari kapasitas angkut dengan armada yang ada, dengan mengunakan metode saving matrix didapat rute distribusi yang lebih efisien dari rute awal sebanyak 8 rute distribusi menjadi 6 rute saja. Dengan 6 rute saja pengiriman barang PLTS area Jawa Barat, didapat juga jarak tempuh yang lebih pendek dengan memangkas $359 \mathrm{~km}$ dari jarak tempuh perusahaan itu membuat rute usulan lebih efisien 23,22\% dari rute perusahaan, dengan jarak tempuh dan rute yang lebih efisien membuat biaya trasnportasi lebih efisien $21,73 \%$ dari biaya transportasi, dan perusahaan dapat menghemat Rp.5.000.000 dari biaya trasportasi yang di lakukan saat ini. Penelitian ini diharapkan dapat memberikan kontribusi bagi aplikasi manajemen operasional perusahaan, terutama manajemen transportasi yang bertujuan untuk mengoptimalkan rute distribusi yang menghemat biaya transportasi.
\end{abstract}

Kata Kunci : Rute Distibusi, Saving Matrix, Biaya Transportasi, Jarak Tempuh. 


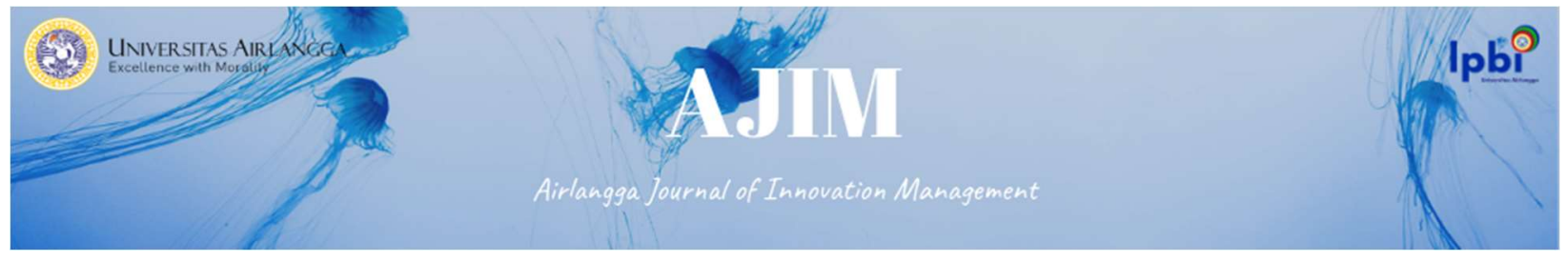

\begin{abstract}
Distribution is one of the important factors for the company to be able to deliver goods appropriately to the project site, so that the distribution of goods is more efficient, then determining the transportation route using the saving Matrix method. The Saving Matrix is a method used to determine the distance, route, time or cost in the delivery of goods by determining the path that the company's problems must follow, namely in shipping goods to the project site. This research is a type of quantitative research with the Saving Matrix calculation method. The results of the study indicate that the process of distributing goods in one shipment of goods to the project location is carried out without first looking at the transport capacity of the existing fleet, using the saving matrix method, a more efficient distribution route is obtained from the initial route of 8 distribution routes to 6 routes only. With only 6 routes for the delivery of goods for PLTS in the West Java area, it is also obtained a shorter distance by cutting $359 \mathrm{~km}$ from the company's mileage, making the proposed route $23.22 \%$ more efficient than the company's route, with more efficient mileage and routes making costs transportation is $21.73 \%$ more efficient than transportation costs, and the company can save Rp.5,000,000 from the current transportation costs. This research is expected to contribute to the company's operational management applications, especially transportation management, which aims to optimize distribution routes that save transportation costs.
\end{abstract}

\title{
Keywords: Distribution Route, Saving Matrix, Transportation Costs, Mileage.
}

\section{PENDAHULUAN}

PT (XYZ) dibangun sejak tahun 2009 dan merupakan perusahaan yang berfokus pada pengembangan energi terbarukan. Sebagai perusahaan EPC (Engineering, Procurement, Construction), XYZ menyediakan sistem solusi total dalam bidang energi terbarukan. Fokus XYZ sejauh ini adalah energi terbarukan tenaga surya, yang akan dikembangkan ke sumber-sumber energi terbarukan lainnya, seperti angin, air, biomassa, dan panas bumi. PTXYX adalah perusahaan yang banyak mengerjakan proyek Pembangunan Pembangkit Listrik Tenaga Surya (PLTS). Distribusi merupakan salah satu faktor penting bagi perusahaan i n i untuk dapat melakukan pengiriman barang secara tepat ke lokasi proyek, ketepatan pengiriman barang ke lokasi proyek harus memiliki rute secara tepat, sehingga barang bisa datang dalam kondisi baik dan tepat waktu ke lokasi proyek, agar kegiatan distribusi barang lebih efisien, maka dilakukan penentuan jalur transportasi dengan metode Saving Matrix.

Saving Matrix merupakan metode yang digunakan untuk menentukan jarak, rute, waktu atau ongkos dalam pelaksanaan pengiriman barang dari perusahaan kepada konsumen dengan cara menentukan jalur yang harus dilalui dan jumlah alat angkut berdasarkan kapasitas dari alat angkut tersebut agar diperoleh jalur yang paling efisien dan biaya transfortasi yang optimum dari perusahaan ke lokasi proyek (Pattiasina dkk, 2018). Namun demikian, terkadang proses pendistribusian barang dalam satu kali pengiriman barang ke lokasi proyek dilakukan tanpa melihat terlebih dahulu dari kapasitas angkut dengan armada yang ada. Sehingga menentukan rute distribusi barang tanpa melihat terdahulu kapasitas dari alat angkut mengakibatkan jalur yang ditempuh tidak efisien (Erlina, 2009). Dengan penyusunan rute yang lebih efisien pendistribusian akan menjadi lebih optimal sehingga dapat mengoptimalkan jarak tempuh, penggunaan alat trasportasi (armada), biaya distribusi dan waktu pengiriman (Indrawati, 2016). 


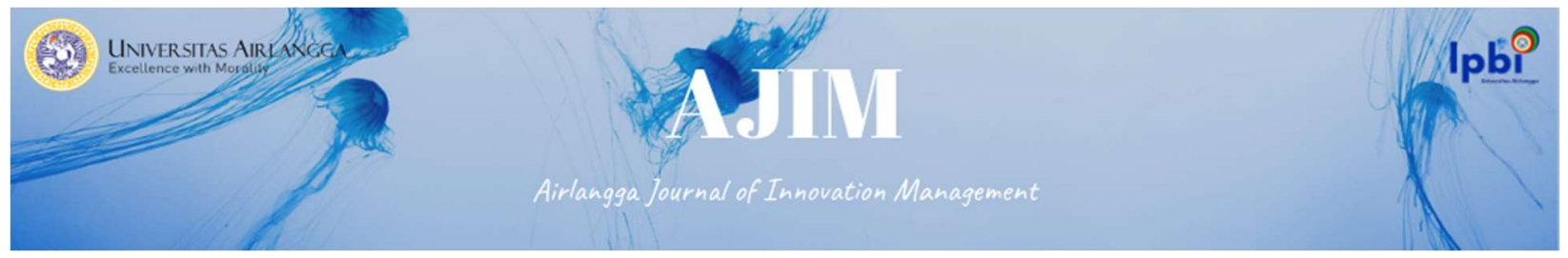

Terdapat beberapa penelitian sebelumnya yang meneliti penggunaan Saving Matrix dalam rangka penurunan biaya distribusi di perusahaan manufaktur. Basuki dkk (2019) dan Fahmi (2013) mengkombinasikan Saving Matrix dan CVRP untuk menentukan rute distribusi optimal menyimpulkan bahwa kedua metode tersebut dapat mengoptimalkan rute distribusi sehingga lebih efisien. Indrawati (2016), menerapkan metode ini untuk menghemat biaya pengiriman sampah. Khadijah \& Wijaya (2020), Kholil dkk (2019) juga menerapkan metode ini di perusahaan manufaktur seperti spareparts dan susu. Pengurangan biaya produksi rata-rata 20-30\% juga dihasilkan oleh penelitian yang dilakukan oleh Pattiasina dkk (2018), Priyambodo dkk (2020), Rizkya dkk (2019) dan Sriwana \& Sari (2013) ketika perusahaan menggunakan metode Saving Matrix.

Berdasarkan penelitian-penelitan tersebut, penelitian bermaksud untuk mengkonfirmasi hasil penelitian sebelumnya, dengan menerapkan perhitungan dengan Saving Matrix di perusahaan penyuplai produk untuk pembangkit listrik tenaga surya di Indonesia. Sehingga penelitian ini diharapkan dapat menjawab permasalahan perusahaan yang membutuhkan suatu jalur pengiriman secara tepat untuk mengurangi pemborosan dalam alat trasnportasi (armada), biaya transportasi serta mendapatkan waktu yang lebih fleksibel, dengan metode saving matrix.

\section{TINJAUAN PUSTAKA}

Umumnya masalah penjadwalan dan penentuan rute pengiriman dapat memiliki beberapa tujuan yang ingin dicapai misalnya untuk meminimalkan biaya pengiriman, meminimalkan waktu, atau meminimalkan jarak tempuh. Dalam bahasa matematika program, salah satu tujuan ini dapat menjadi tujuan fungsi (fungsi tujuan) dan lainnya menjadi kendala (paksaan). Misalnya, fungsi tujuan adalah untuk meminimalkan biaya pengiriman, tetapi ada jendela waktu kendala dan kendala jarak tempuh maksimum per kendaraan, dalam Selain kendala lain seperti kapasitas kendaraan atau lainnya kendala (Pattiasina dkk, 2018).

Distribusi adalah kegiatan untuk memindahkan produk dari pihak suplier kepada konsumen dalam bentuk suatu supply chain. Distribusi merupakan suatu kunci keuntungan yang akan di peroleh perusahaan karena distribusi secara langsung akan mempengaruhi biaya dari supply chain dan kebutuhan konsumen, jaringan distribusi yang tepat dapat digunakan untuk mencapai berbagai macam dari kebutuhan supply chain mulai dari biaya yang rendah dan respons yang tinggi terhadap permintaan konsumen.Istilah distribusi sama dengan place (penempatan) yaitu aktivitas penyaluran atau penempatan barang (produk) dari produsen ke konsumen. Perpindahan material terjadi pada semua siklus proses manufaktur produk, baik itu sebelum maupun sesudah proses produksi (Lubis,2004)

Manajemen transportasi dan distribusi merupakan pengolahan terhadap kegiatan untutuk pergerakan suatu produk dari satu lokasi ke lokasi lain yang dimana pergerakan tersebut biasanya membentuk atau menghasilkan suatu jaringan (Paularine, 2018). Pada kebanyakan produk, peran jaringan distribusi dan distribusi sangatlah vital. Jaringan distribusi dan transpotasi ini memungkinkan produk pindah dari lokasi dimana mereka di produksi ke lokasi konsumen yang sering kali di batasi oleh jarak yang jauh. Kemampuan untuk mengirimkan produk ke konsumen secara tepat waktu, dalam jumlah yang sesuai dan dalam kondisi yang sangat baik menentukan apakah pada akhirnya produk tersebut kompetitif di pasar. Kemampuan untuk mengelolah jaringan distribusi ini merupakan suatu komponen unggulan kompetitif yang sangat penting bagi kebanyakan industri.

Kegiatan distribusi dan transportasi dapat di lakukan oleh perusahaan manufaktur dengan 


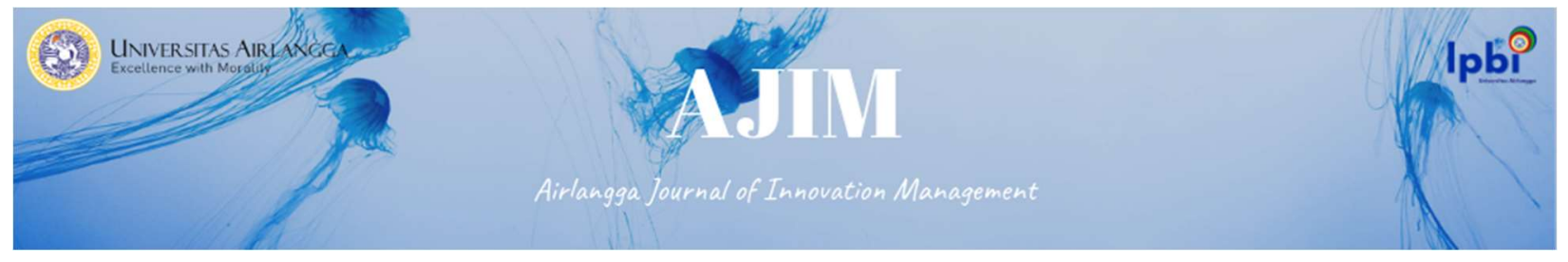

membentuk bagian distribusi atau transportasi sendiri atau di serahkan pihak ketiga (Suwarno, 2006). Dalam upayanya untuk memenuhi tujuan - tujuan di atas, siapapun yang melaksanakan (internal perusahaan atau mitra pihak ke tiga), manajemen distribusi dan transportasi pada umumnya melakukan sejumlah fungsi dasar yang terdiri dari :

1. Melakukan segmentasi dan melakukan target service level. Segmentasi konsumen perlu di lakukan karena kontribusi mereka pada revenue perusahaan bisa bervariasi dan karakteristik tiap konsumen bisa bebeda satu dengan lainya. Dengan memahami perbedaan karakteristik dan kontribusi tiap konsumen atau area distribusi, perusahaan bisa mengoptimalkan alokasi persediaan 11 maupun kcepatan layanan. Misalnya, konsumen kelas 1, yang menyumbangkan pendapatan terbesar, memiliki target servis level yang lebih tinggi di bandingkan dengan konsumen kelas 2 atau kelas 3 yang kontribusinya lebih rendah.

2. Menentukan mode transportasi yang akan di gunakan. Tiap mode transportasi memiliki karakteristik yang beda dan memiliki keunggulan serta kelemahan yang berbeda juga, sebagai contoh, transportasi laut memiliki keunggulan dari segi biaya yang lebih rendah, namun lebih lambat di bandingkan dengan transportasi udara. Manajemen transportasi harus bisa menentukan mode apa yang akan di gunakan dalam mengirimkan produk - produk mereka ke konsumen, kombinasi dua atau lebih mode transportasi tentu bisa atau bahkan harus di lakukan tergantung pada situasi yang di hadapi.

3. Melakukan penjadwalan dan penetuan rute pengiriman. Salah satu kegiatan yang di lakukan oleh distributor adalah menetukan kapan kendaraan harus berangkat dan rute mana yang harus di lalui untuk memenuhi permintaan dari sejumlah konsumen. Apabila jumlah konsumen sedikit, keputusan ini dapat di ambil secara mudah. Namun perusahaan yang memiliki ribuan atau puluhan ribu toko atau tempat - tempat penjualan yang harus di kunjungi, penjadwalan dan penentuan rute pengiriman adalah pekerjaan yang sangat sulit dan kurang tepatan dalam mengambil dua keputusan tersebut bisa berimplikasi pada biaya pengiriman.

\section{Metode Penentuan Rute dan Jadwal Pengiriman.}

Salah satu keputusan operasional yang sangat penting dalam manajemen distribusi adalah penentuan jadwal rute pengiriman dari satu lokasi ke beberapa lokasi tujuan. Keputusan seperti ini sangat penting bagi mereka yang harus mengirimkan barang dari satu lokasi (misalnya gedung regional) ke berbagai toko yang tersebar di sebuah kota. Keputusan jadwal pengiriman serta rute yang akan di tempuh oleh tiap kendaraan akan sangat berpengaruh terhadap biaya - biaya pengiriman. Namun demikian, biaya bukanlah satu - satunya faktor pertimbangan dalam proses pengiriman, namun juga harus mempertimbangkan jarak tempuh juga, dalam bahasa program matematis, salah satu tujuan tersebut bisa menjadi fungsi tujuan (objective function) dan lainya menjadi kendala (constraint) (Ritonga dkk, 2015). Misalnya, fungsi tujuanya adalah meminimumkan biaya pengiriman namun ada kendala - kendala di antaranya jumlah truk yang banyak dengan perbedaan kapasitas, perbedaan kecepatan dalam zona yang berbeda, rintangan/penghalang dalam perjalanan (sungai, belokan, gunung), dan waktu istirahat untuk pengemudi adalah beberapa pertimbangan yang diperlukan dalam penentuan perancangan rute. Pekerjaan yang harus dilakukan adalah menentukan alokasi truk, artinya perlu di ketahui truk mana yang akan mengunjungi toko yang mana. Tahap kedua nantinya adalah menentukan rute perjalanan masing - masing truk. Untuk menentukan rute yang paling baik dapat di kerjakan denagn satu metode yang di namkan metode saving matrix. 


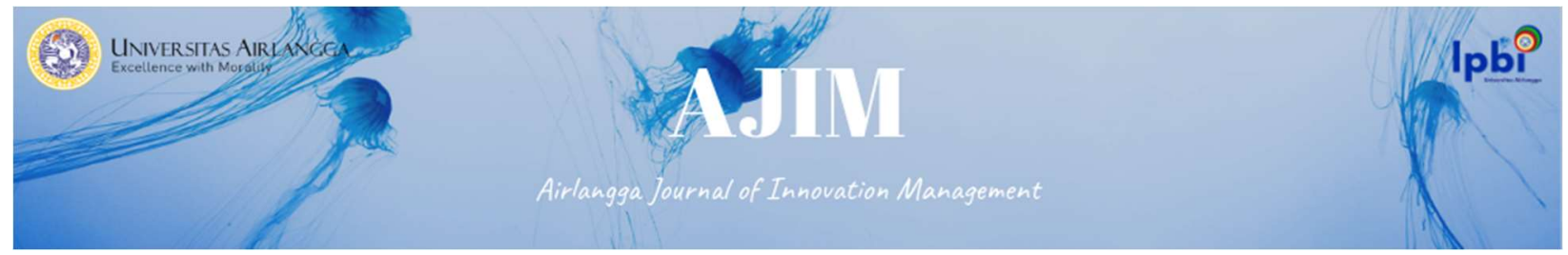

\section{Metode Saving Matrix}

Metode Saving Matrix merupakan salah satu metode yang mudah diterapkan untuk masalah distribusi yang kompleks segera. Keuntungan dari metode ini terletak pada kemudahan modifikasinya. Jika ada kendala seperti kapasitas kendaraan, jumlah kendaraan, waktu pengiriman atau kendala lain, dapat memberikan yang cepat dan solusi praktis meskipun hasilnya tidak menjamin solusi optimal. Dalam penerapan pada metode Saving Matrix ada tahapan yang harus dilakukan yaitu sebagai berikut:

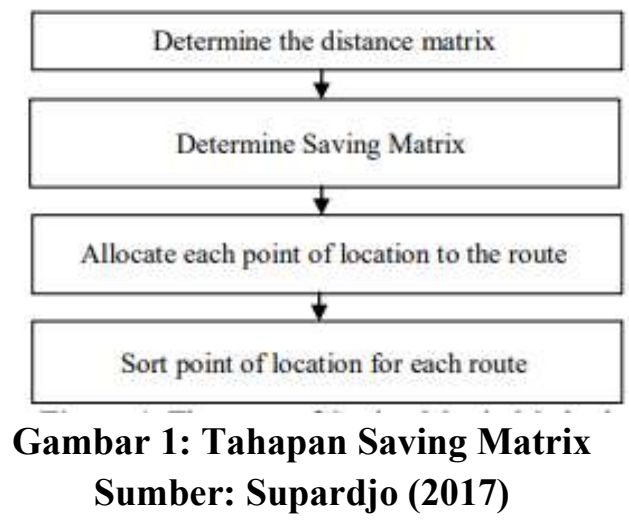

Kelebihan dari metode saving matrix ini terletak pada kemudahan untuk dimodifikasi jika terdapat batasan waktu pengiriman, kapasitas kendaraan, jumlah kendaraan atau batasan lain yang memberikan solusi yang lebih baik untuk menyelesaikan penjadwalan pengiriman dengan praktis dan cepat (Yunarti, 2013)

\section{METODE PENELITIAN}

Objek penelitian adalah pengiriman barang peralatan pembangunan PLTS SEISMIC di area Jawa Barat yang dilakukan di PT.XYZ. dalam pengerjaannya, penelitian ini dilakukan dengan melakukan analisis sistem pengiriman barang dengan membandingkan metode saving matrix dengan metode yang dilakukan perusahaan. Data-data yang dibutuhkan adalah data primer dari biaya total yang dikeluarkan dalam proses pengiriman barang perusahaan ke lokasi proyek, data kapasitan angkutan transportasi adalah data volume barang yang bisa diangkut dalam sekali angkutan. Data jarak antara setiap titik lokasi proyek adalah data yang menunjukan jarak antara lokasi proyek pembanguan PLTS satu dengan titik lokasi proyek pembanguna PLTS yang lain, diarea Jawa Barat. Data-data yang digunakan dalam analisa untuk penentuan rute pengiriman barang ke lokasi proyek didapat melalui pengamatan dan dokumentasi yang dilakukan dilapangan serta berdasarkan data yang dimiliki perusahan.

\section{ANALISIS DAN PEMBAHASAN Pengumpulan Data}

Data yang digunakan dalam penelitian adalah seperti pada table dibawah ini Pengirimanan barang 


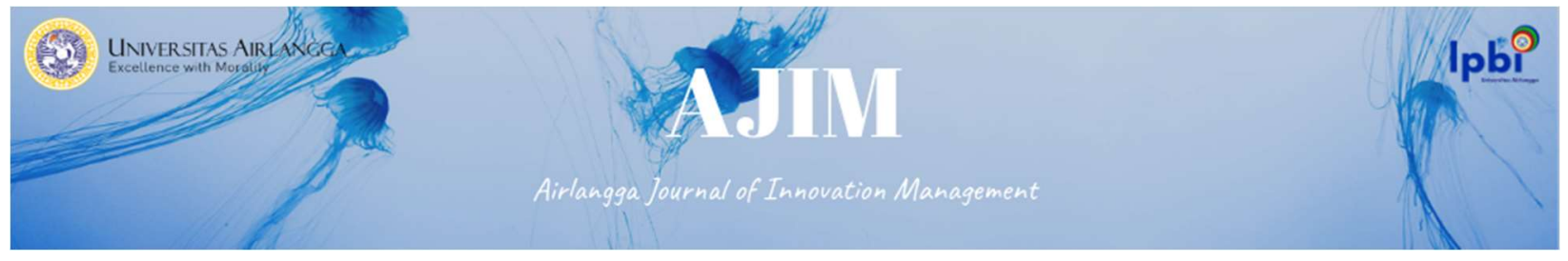

dilakukan ke 15 titik lokasi proyek dengan data sesuai table 3.1

Tabel 1 Data Lokasi Proyek Pembanguan PLTS SEISMIC Area Jawa Barat

\begin{tabular}{|l|l|l|}
\hline No & Kode Lokasi & Lokasi \\
\hline 1 & PSJM & Pelabuhan ratu \\
\hline 2 & WSJM & Warungkiara \\
\hline 3 & CSJI & Ciracap \\
\hline 4 & JTJI & Jampang tengah \\
\hline 5 & SSJM & Suka raja \\
\hline 6 & CCJM & Cempaka \\
\hline 7 & SCJM & Sukaluyu \\
\hline 8 & CBJM & Cipongkor \\
\hline 9 & PBJI & Pasir jambu \\
\hline 10 & CWJM & Cikalong wetan \\
\hline 11 & JPJI & Jatiluhur \\
\hline 12 & TSJM & Tanjungsiang \\
\hline 13 & BSJI & Tomo \\
\hline 14 & CSJM & Congeang \\
\hline 15 & CIJM & Cikedung \\
\hline 16 & PKJM & Pasawahan \\
\hline 17 & ACJM & Astana anyar \\
\hline 18 & SEJM & Sedong \\
\hline 19 & PCJM & Pabuaran \\
\hline 20 & BKJI & Banjar \\
\hline 21 & ITJI & Cipedes \\
\hline & S & \\
\hline
\end{tabular}

Sumber: Data diolah penulis (2020)

Table 2 Data Rute Pengiriman Barang PLTS SEISMIC Area Jawa Barat

\begin{tabular}{|l|l|c|}
\hline No & Rute & $\begin{array}{l}\text { Total } \\
\text { Jarak } \\
\text { (KM) }\end{array}$ \\
\hline 1 & Gudang - jtji-wsjm-psjm & 188 \\
\hline 2 & Gudang - pbji- scji & 229 \\
\hline 3 & Gudang -scjm-ssjm-ccjm & 148 \\
\hline 4 & Gudang -cbjm-cwjm-jpji & 136.5 \\
\hline 5 & Gudang -tsjm-bsji-csjm & 118 \\
\hline 6 & Gudang -pkjm-cijm & 281 \\
\hline 7 & Gudang -acjm-sejm-pcjm & 272 \\
\hline 8 & Gudang -itji-bkji & 181 \\
\hline
\end{tabular}




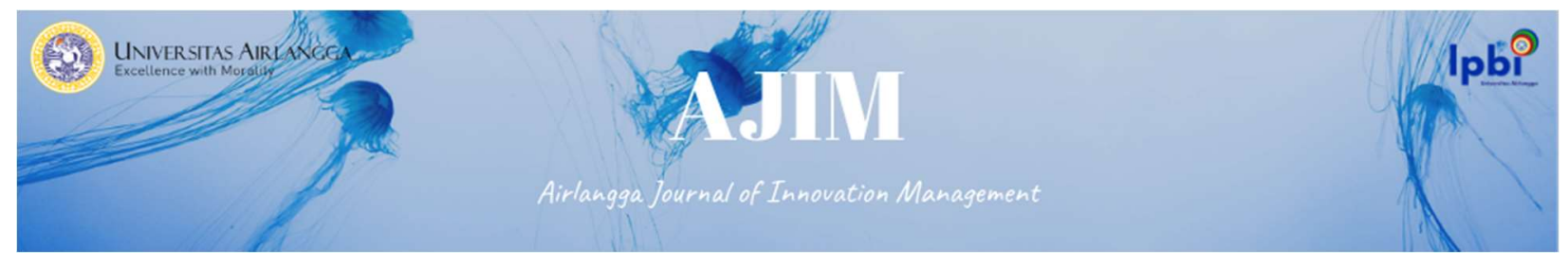

Total

1553.5

Sumber: Data diolah penulis (2020)

Tabel 3 Total Biaya Transportasi Pengiriman Barang PLTS SEISMIC Area Jawa Barat

\begin{tabular}{|l|l|l|l|}
\hline No & Rute & Leadtime & \multicolumn{1}{|c|}{ Biaya/Trip } \\
\hline 1 & Rute 1 & 3 Hari & Rp3,000,000 \\
\hline 2 & Rute 2 & 3 Hari & Rp3,000,000 \\
\hline 3 & Rute 3 & 3 Hari & Rp3,000,000 \\
\hline 4 & Rute 4 & 3 Hari & Rp3,000,000 \\
\hline 5 & Rute 5 & 3 Hari & Rp3,000,000 \\
\hline 6 & Rute 6 & 3 Hari & Rp3,000,000 \\
\hline 7 & Rute 7 & 3 Hari & Rp3,000,000 \\
\hline 8 & Rute 8 & 2 Hari & Rp2,000,000 \\
\hline \multicolumn{3}{|c|}{ Total Biaya } & Rp23,000,000 \\
\hline
\end{tabular}

Sumber: Data diolah penulis (2020)

\section{Pengolahan Data}

\section{Analisa Rute Distibusi Dan Jarak Tempuh}

Pada bagian ini dilakukan perbandingan biaya transportasi dan jarak tempuh yang dilakukan perusahaan dengan metode yang diusulkan yaitu metode saving matrix. Dengan perbandingkan itu diharapkan metode saving matrix bisa menghasilkan biaya trasnportasi dan jarak tempuh yang lebih efisien.

Tabel 4 Perbandingan Jarak Distribusi Dan Rute Usulan

\begin{tabular}{|c|c|c|c|c|c|}
\hline No & $\begin{array}{l}\text { Rute Exsisting } \\
\text { Perusahaan }\end{array}$ & $\begin{array}{l}\text { Jarak Tempuh } \\
\text { Exsisiting } \\
\text { Perusahan (KM) }\end{array}$ & No & Rute Usulan & $\begin{array}{l}\text { Jarak } \\
\text { Tempuh } \\
\text { Usulan } \\
\text { (KM) }\end{array}$ \\
\hline 1 & $\begin{array}{l}\text { Gudang -jtji-wsjm- } \\
\text { Psjm }\end{array}$ & 188 & 1 & $\begin{array}{l}\text { Gudang - jtji-wsjm-psjm- } \\
\text { scji }\end{array}$ & 253 \\
\hline 2 & Gudang - pbji- scji & 229 & 2 & Gudang -scjm-ssjm-ccjm & 148 \\
\hline 3 & $\begin{array}{l}\text { Gudang -scjm-ssjm- } \\
\text { Ccjm }\end{array}$ & 148 & 3 & $\begin{array}{l}\text { Gudang -scji-cbjm-cwjm- } \\
\text { JPJI }\end{array}$ & 147.5 \\
\hline 4 & $\begin{array}{l}\text { Gudang -cbjm-cwjm- } \\
\text { JPJI }\end{array}$ & 136.5 & 4 & $\begin{array}{l}\text { Gudang -tsjm-bsji-csjm- } \\
\text { cijm }\end{array}$ & 175 \\
\hline 5 & $\begin{array}{l}\text { Gudang -tsjm-bsji- } \\
\text { csjm }\end{array}$ & 118 & 5 & $\begin{array}{l}\text { Gudang -pkjm-acjm-sejm- } \\
\text { pcjm }\end{array}$ & 290 \\
\hline 6 & Gudang -pkjm-cijm & 281 & 6 & Gudang -itji-bkji & 181 \\
\hline 7 & $\begin{array}{l}\text { Gudang -acjm-sejm- } \\
\text { pcjm }\end{array}$ & 272 & & & \\
\hline
\end{tabular}




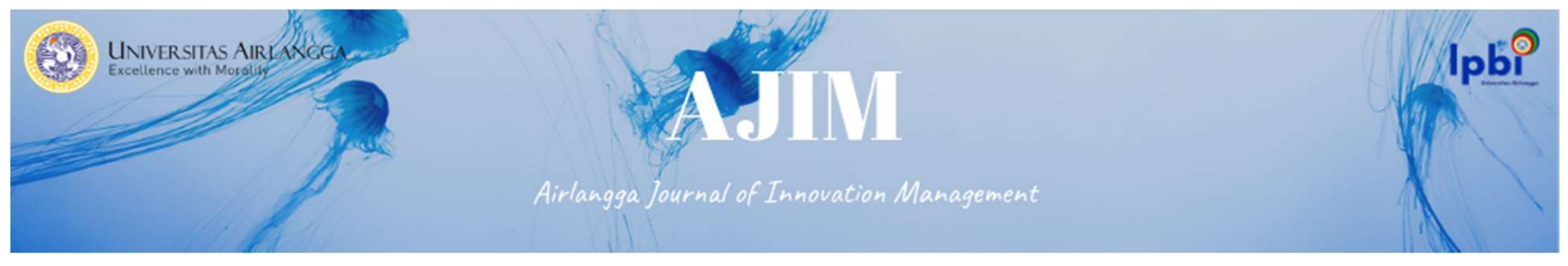

\begin{tabular}{|l|l|l|l|l|l|}
\hline 8 & Gudang -itji-bkji & 181 & & & \\
\hline Total & 1553.5 & & Total & 1194.5 \\
\hline
\end{tabular}

Sumber: Data diolah penulis (2020)

Dari Table 4 didapat total jarak tempuh yang lebih efisien yang didapat dengan penentuan rute yang lebih efisien dengan metode saving matrix dengan mengunakan jarak tempuh usulan maka di dapat efisiensi jarak sebagai berikut:

$$
\text { Efisiensi jarak }=\frac{1553.5-1194.5}{1553.5} \times 100 \%=23,22 \%
$$

Dari hasil perbandingan antara jarak tempuh dengan rute perusahaan dengan rute usulan didapat efisiensi jarak sebesar 23,22\% dari jarak tempuh perusahaan, dan hasil ini tentu akan mengurangi juga jumlah armada angkutan yang semula 8 mobil menjadi hanya 6 mobil angkutan saja

\section{Analisa Biaya Transportasi}

Dari hasil analisa jarak tempuh dan rute yang lebih efisien, dengan jarak tempuh yang semakin pendek, maka pasti berpengaruh juga terhadap biaya transportasi yang pasti akan bisa lebih hemat. Pada tabel 3.5 akan dianalisa perbadingan antara biaya trasnportasi perusahaan dengan biaya transportasi yang diusulkan menggunakan metode saving matrix.

Tabel 5 Analisa Biaya

\begin{tabular}{|c|c|c|c|c|c|c|c|}
\hline \multicolumn{4}{|c|}{ Biaya Transportasi Perusahaan } & \multicolumn{4}{|c|}{ Biaya Transportasi Usulan } \\
\hline No & Rute & Leadtime & Biaya/Trip & No & Rute & Leadtime & Biaya/Trip \\
\hline 1 & Rute 1 & 3 hari & $\mathrm{Rp} 3,000,000$ & 1 & Rute 1 & 3 hari & Rp3,000,000 \\
\hline 2 & Rute 2 & 3 hari & Rp3,000,000 & 2 & Rute 2 & 3 hari & Rp3,000,000 \\
\hline 3 & Rute 3 & 3 hari & Rp3,000,000 & 3 & Rute 3 & 3 hari & Rp3,000,000 \\
\hline 4 & Rute 4 & 3 hari & $\mathrm{Rp} 3,000,000$ & 4 & Rute 4 & 3 hari & Rp3,000,000 \\
\hline 5 & Rute 5 & 3 hari & $\mathrm{Rp} 3,000,000$ & 5 & Rute 5 & 3 hari & $\mathrm{Rp} 3,000,000$ \\
\hline 6 & Rute 6 & 3 hari & Rp3,000,000 & 6 & Rute 6 & 3 hari & Rp3,000,000 \\
\hline 7 & Rute 7 & 3 hari & Rp3,000,000 & & & & \\
\hline 8 & Rute 8 & 2 hari & $\mathrm{Rp} 2,000,000$ & & & & \\
\hline \multicolumn{3}{|c|}{ Total Biaya } & Rp23,000,000 & \multicolumn{3}{|c|}{ Total Biaya } & Rp18,000,000 \\
\hline
\end{tabular}

Sumber: Data diolah penulis (2020)

Dari tabel 5 jumlah rute yang lebih sedikit dan jarak tempuh yang lebih pendek maka akan lebih menghemat biaya trasnportasi, melalui biaya tranportasi usulan yang mengunakan metode saving matrix maka perusahaan dapat melakukan penghematan Rp.5.000.0000. Dengan perbandingan biaya trasnportasi perusahaan dengan biaya trasnportasi usulan maka didapat efisiensi biaya trasnportasi sebagai berikut: Efisiensi biaya transportasi 


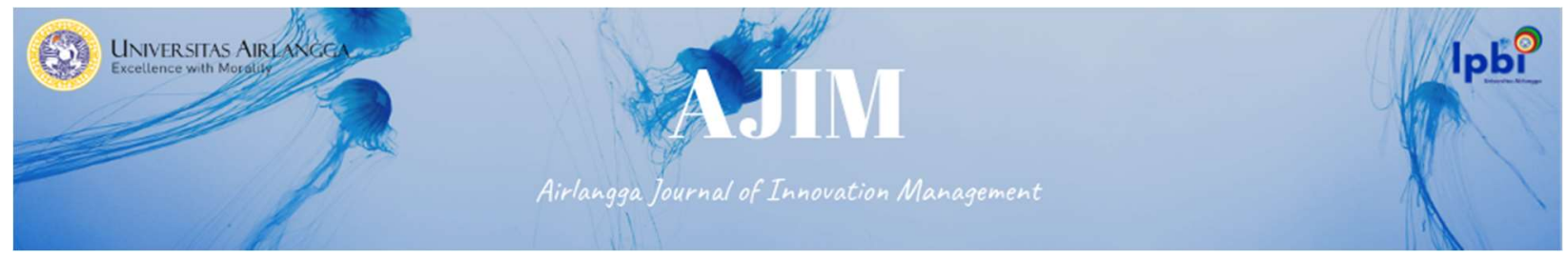

$$
=\mathrm{Rp} .23 .000 .000-\mathrm{Rp} .18 .000 .000 \times 100 \%=21,73 \%
$$

Rp.23.000.000

Dari biaya trasnportasi usulan yang menggunakan metode saving matrix didapat efisiensi sebesar 21,73\% dari biaya trasportasi perusahaan.

Dari hasil perhitungan ini, penelitian ini mendukung hasil penelitian sebelumnya dari Pattiasina dkk (2018), Priyambodo dkk (2020), Rizkya dkk (2019) dan Sriwana \& Sari (2013) yang menyatakan bahwa perusahaan dapat menghemat biaya transportasi sebesar $20-30 \%$ dengan menggunakan metode Saving Matrix dalam perencanaan distibusi produk perusahaan.

\section{KESIMPULAN}

Dari analisa dan pembahan yang dilakukan dengan mengunakan metode saving matrix didapat rute distribusi yang lebih efisien dari rute awal sebanyak 8 rute distribusi menjadi 6 rute saja. Dengan 6 rute saja pengiriman barang PLTS area Jawa Barat, didapat juga jarak tempuh yang lebih pendek dengan memangkas $359 \mathrm{~km}$ dari jarak tempuh perusahaan, itu membuat rute usulan lebih efisien 23,22\% dari rute perusahaan, dengan jarak tempuh dan rute yang lebih efisien membuat biaya trasnportasi lebih efisien $21,73 \%$ dari biaya transportasi, dan perusahaan dapat menghemat Rp.5.000.000 untuk biaya trasportasi yang dilakukan saat ini. Saran untuk penelitian selanjutnya, Metode Saving Matrix dapat diterapkan dengan kombinasi metode yang lain seperti CVRP yang akan lebih mengoptimalkan rute distribusi dan menghemat biaya distribusi.

\section{DAFTAR PUSTAKA}

Basuki, M., Hidayat, M. J., \& Aji, F. B. (2019). Application of saving matrix methods and cross entropy for capacitated vehicle routing problem (CVRP) resolving. In IOP Conference Series: Materials Science and Engineering (Vol. 462, No. 1, p. 012025). IOP Publishing.

Chrystianto, H., Adianto, H., \& Rispianda, R. (2013). Usulan Rute Distribusi Roti Dengan Menggunakan Metode Clarke-Wright Algorithm. REKA INTEGRA, 1(1).

Erlina, P. (2009). Mengoptimalkan Biaya Transportasi Untuk Penentuan Jalur Distribusi. Jurnal Penelitian Ilmu Teknik, 9(2), 143-150.

Fahmi, E. (2013). Studi Komparasi Penyelesaian Capacitated Vehicle Routing Problem (CVRP) dengan Metode Saving Matrix dan Generalized Assignment (Doctoral dissertation, Universitas Brawijaya).

Indrawati, I. (2016, August). Determination of Optimal Routes on Garbage Transportation by Using Saving Matrix Method. In The 4th International Conference on Mathematical Sciences.

Khadijah, A., Syarifudin, A., \& Wijaya, H. (2020, March). Determination of Distribution Products Using Matrix Saving Method in the Serang Marketing Office Area. In 1st International Multidisciplinary Conference on Education, Technology, and Engineering (IMCETE 2019) (pp. 328-331). Atlantis Press.

Kholil, M., Mangaraja, R. D., \& Yosan, R. B. (2019, March). Improving the Efficiency of the Milkrun Truck 


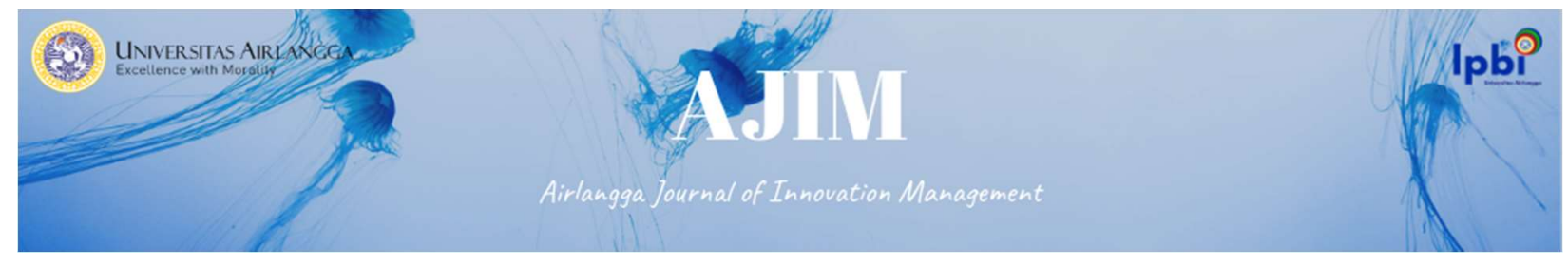

Suppliers in Cikarang Area by Merging the Payload Cycles and Optimizing the Milkrun Route Using the Saving Matrix Methods. In Journal of Physics: Conference Series (Vol. 1175, No. 1, p. 012201). IOP Publishing.

Pakaja, F., Naba, A., \& Purwanto, P. (2012). Peramalan Penjualan Mobil Menggunakan Jaringan Syaraf Tiruan dan Certainty Factor. Jurnal Eeccis, 6(1), 23-28.

Pattiasina, T. J., Setyoadi, E. T., \& Wijayanto, D. (2018). Saving matrix method for efficient distribution route based on google maps API. Journal of Telecommunication, Electronic and Computer Engineering (JTEC), 10(2-3), 183-188.

Paularine, G. F. (2018). Analisis Biaya Operasional Distribusi Rak Buku Di Daerah Kabupaten Bandung Barat Menggunakan Metode Saving Matriks Pada Pt Xyz (Doctoral Dissertation, Universitas Widyatama).

Pramita, W., \& Tanuwijaya, H. (2015, July). Penerapan Metode Exponential Smoothing Winter Dalam Sistem Informasi Pengendalian Persediaan Produk Dan Bahan Baku Sebuah Cafe. In Seminar Nasional Informatika (SEMNASIF) (Vol. 1, No. 5).

Priyambodo, G. A., Hamdani, M. A., Akbar, T. G., \& Suprapto, A. T. (2020). OPTIMIZATION DISTRIBUTION ROUTES AND DELIVERY COSTS WITH TRANSPORTATION AND SAVING MATRIX METHODS. Business Management Journal, 15(2).

Raharja, A., Angraeni, W., \& Vinarti, R. A. (2010). Penerapan Metode Exponential Smoothing Untuk Peramalan Penggunaan Waktu Telepon Di PT. Telkomsel Divre3 Surabaya. Jurnal Sistem Informasi.

Rahmayanti, D., \& Fauzan, A. (2016). Optimalisasi sistem persediaan bahan baku karet mentah (lateks) dengan metode Lot Sizing (studi kasus: PT Abaisiat Raya). Jurnal Optimasi Sistem Industri, 12(1), 317-325.

Ritonga, D., Timboeleng, J. A., \& Kaseke, O. H. (2015). Analisa Biaya Transportasi Angkutan Umum Dalam Kota Manado Akibat Kemacetan Lalu Lintas (Studi Kasus: Angkutan Umum Trayek Pusat Kota 45Malalayang). Jurnal Sipil Statik, 3(1).

Rizkya, I., Matondang, N., Yahya, M. D., \& Ningsih, M. S. (2019, August). Design of Distribution Routes Using Saving Matrix Method to Minimize Transportation Cost. In 2019 International Conference on Sustainable Engineering and Creative Computing (ICSECC) (pp. 48-51). IEEE.

Rosanti, A. A., Sutopo, W., \& Hisjam, M. (2019, April). Implementation of saving matrix to determine distribution route of Kalog Express Surakarta. In IOP Conference Series: Materials Science and Engineering (Vol. 495, No. 1, p. 012025). IOP Publishing.

Soedjianto, F., Oktavia, T., \& Anggawinata, J. A. (2006). Perancangan dan Pembuatan Sistem Perencanaan Produksi (Studi Kasus Pada PT. Vonita Garment). In Seminar Nasional Aplikasi Teknologi Informasi (SNATI).

Sriwana, I. K., Madusari, S., \& Sari, N. A. (2013, February). Spare Parts Distribution Route Planning with Saving Matrix Method at PT XYZ. In Proceding of 6th International Seminar on Industrial 


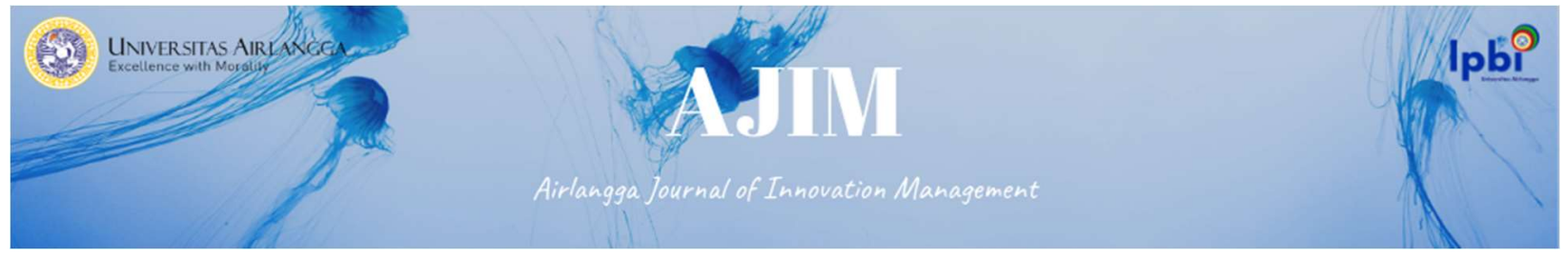

Engineering and Management (ISIEM).

Suparjo, 2017 , Metode Saving Matrix sebagai metode alternatif untuk efisiensi biaya distribusi, https://media.neliti.com/media/public ations/150669-ID-metode-saving- matrix-sebagai-alternatif.pdf

Suwarno, H. L. (2006). Sembilan Fungsi Saluran Distribusi: Kunci Pelaksanaan Kegiatan Distribusi Yang Efektif. Jurnal Manajemen Maranatha, 6(1), 79-87.

Yuniarti, R., \& Astuti, M. (2013). Penerapan metode saving matrix dalam penjadwalan dan penentuan rute distribusi premium di SPBU Kota Malang. Rekayasa Mesin, 4(1), 17-26. 